\title{
Inability of rat DPP4 to allow MERS-CoV infection revealed by using a VSV pseudotype bearing truncated MERS-CoV spike protein
}

\author{
Aiko Fukuma $^{1}$ - Hideki Tani ${ }^{1} \cdot$ Satoshi Taniguchi $^{1} \cdot$ Masayuki Shimojima $^{1}$. \\ Masayuki Saijo $^{1} \cdot$ Shuetsu Fukushi $^{1}$
}

Received: 19 May 2015/ Accepted: 18 June 2015/Published online: 4 July 2015

(C) Springer-Verlag Wien 2015

\begin{abstract}
Middle East respiratory syndrome (MERS) coronavirus $(\mathrm{Co}-\mathrm{V})$ contains a single spike (S) protein, which binds to a receptor molecule, dipeptidyl peptidase 4 (DPP4; also known as CD26), and serves as a neutralizing antigen. Pseudotyped viruses are useful for measuring neutralization titers against highly infectious viruses as well as for studying their mechanism of entry. In this study, we constructed a series of cytoplasmic deletion mutants of MERS-CoV S and compared the efficiency with which they formed pseudotypes with vesicular stomatitis virus. A pseudotype bearing an S protein with the C-terminal 16 amino acids deleted (MERSpv-St16) reached a maximum titer that was approximately tenfold higher than that of a pseudotype bearing a nontruncated full-length S protein. Using MERSpv-St16, we demonstrated the inability of rat DPP4 to serve as a functional receptor for MERS-CoV, suggesting that rats are not susceptible to MERS-CoV infection. This study provides novel information that enhances our understanding of the host range of MERS-CoV.
\end{abstract}

\section{Introduction}

Middle East respiratory syndrome coronavirus (MERS$\mathrm{CoV}$ ) is the etiological agent responsible for MERS, a severe respiratory disease first reported in the Middle East

Electronic supplementary material The online version of this article (doi:10.1007/s00705-015-2506-z) contains supplementary material, which is available to authorized users.

Shuetsu Fukushi

fukushi@nih.go.jp

1 Department of Virology 1, National Institute of Infectious Diseases, 4-7-1 Gakuen, Musashimurayama,

Tokyo 208-0011, Japan in 2012 [25]. So far, MERS patients have mainly been identified in and near the Arabian Peninsula. However, there have also been many cases in other countries in travelers who had visited the Arabian Peninsula [8, 11, 22]. This virus has spread from ill people to others through close contact with infected individuals [1]. The detection of MERS-CoV RNA and the high seroprevalence of antibodies to MERS-CoV in dromedary camels in the Middle East raise the possibility that these animals may be natural/ amplification hosts preceding human infection [16, 21]. Genetically, MERS-CoV resembles the SARS coronavirus (SARS-CoV), the causative agent for an outbreak of severe acute respiratory disease that occurred in humans in 2002-2003. Therefore, the spread of MERS-CoV infection has raised serious concerns for a potential global pandemic.

In vitro studies have indicated that a variety of cells, originating from bats, pigs, and non-human primates, are susceptible to MERS-CoV infection [5, 14]. However, the ability of the virus to infect cells from a mice, hamsters, and ferrets was restricted [23]. Although mice are not susceptible to MERS-CoV infection, transient expression of human DPP4 in the respiratory tract using a recombinant adenovirus has facilitated the development of a small animal model of MERS for understanding the immune responses against MERS-CoV infection [27]. Also, the susceptibility of rhesus macaques and common marmosets to MERS-CoV infection has been investigated to understand the pathogenesis of MERS-CoV [7, 15].

MERS-CoV infection in susceptible cells is mediated by the binding of the viral spike (S) protein to its receptor molecule, dipeptidyl peptidase 4 (DPP4), also known as CD26 [19]. Crystal structure modeling of the receptorbinding domain (RBD) of MERS-CoV S interacting with human DPP4 revealed the amino acid residues in human DPP4 that are critical for binding to S [12, 24]. A site- 
directed mutagenesis study of mouse DPP4 revealed the critical amino acids that regulate the species specificity of MERS-CoV infection in mice [6]. While the receptor function of DPP4 from mice and hamsters has been investigated in detail $[6,23]$, to date, there has been no report about DPP4 from rats, another commonly used small-animal model, regarding its potential to function as a receptor for MERS-CoV.

Studies of MERS-CoV infection have been limited because of the highly infectious nature of the virus. Replication-incompetent pseudotyped viruses bearing viral glycoproteins are advantageous because they can be used without heightened biocontainment for investigating virus entry into cells, viral tropism, and the effects of entry inhibitors. A pseudotyped virus is also useful for measuring neutralization titers against highly infectious viruses. Pseudotypes based on vesicular stomatitis virus (VSV) have advantages compared with other pseudotypes based on lentiviruses. First, the pseudotype virus titer obtained with the VSV system is generally higher than that obtained with the retrovirus system [17]. Second, the infection of target cells with the VSV pseudotype can be readily detected as GFP-positive cells at 7-16 h postinfection because of the high level of GFP expression in the VSV system [9]. In contrast, the time required for infection in the retrovirus system is $40-72 \mathrm{~h}[13,26]$, which is similar to the time required for live viruses to replicate to a level that results in plaque-forming or cytopathic effects in infected cells. Pseudotypes based on VSV may be applicable not only for the rapid detection of neutralizing antibodies but also for investigating virus entry into a variety of cells. In view of previous findings that a SARS-CoV S protein variant with a shortened cytoplasmic domain is efficiently incorporated into VSV particles [9], the carboxyl-terminal truncation of the MERS-CoV $\mathrm{S}$ protein might provide a high titer of the VSV-based MERS-CoV S-bearing pseudotype (MERSpv).

In this study, we constructed a series of carboxyl-terminal truncations of the MERS-CoV S and determined the efficiency with which they formed MERSpv with a shortened S protein. We then used the MERSpv to investigate the ability of rat-derived DPP4 to serve as a receptor for MERS-CoV.

\section{Materials and methods}

\section{Cells and viruses}

Vero, Huh-7, CHO and 293T cells were routinely subcultured in cell culture flasks in Dulbecco's modified Eagle's medium (DMEM, Sigma, St. Louis, MO) supplemented with $100 \mathrm{U}$ of penicillin per $\mathrm{ml}, 100 \mu \mathrm{g}$ of streptomycin per $\mathrm{ml}$, and $5 \%(\mathrm{v} / \mathrm{v})$ fetal bovine serum (FBS). The cells were maintained at $37^{\circ} \mathrm{C}$ in an atmosphere of $5 \% \mathrm{CO}_{2}$. MERS-CoV isolate HCoV-EMC/2012 (kindly provided by Dr. Bart Haagmans and Dr. Ron Fochier, Erasmus Medical Center, Rotterdam, The Netherlands) was used in the present study.

\section{Plasmids}

MERS-CoV cDNA was obtained by reverse transcription of total RNA isolated from MERS-CoV-infected Vero cells. The full-length cDNA of the MERS-CoV S protein was amplified using the forward primer $\mathrm{S}$ infusion-F (5'cgactctagaggatccegtgacaatgatacactcagtgtttctactga-3') and the reverse primer CoV-S-F (5'-tatcatgtctggatccttagtgaacatgaaccttatgc-3'), and the product was cloned into the Bam HI site of the mammalian expression vector pKS336 [9], using an In-Fusion HD Cloning Kit (Clontech Laboratories, Mountain View, CA). The resulting plasmid was designated pKS-MERS-S. The cDNAs with truncated C-termini (deletions of regions corresponding to 7, 11, 16, or 20 amino acid residues) were amplified from pKSMERS-S using the forward primer $\mathrm{S}$ infusion- $\mathrm{F}$ and the reverse primer St7-R (5'-tatcatgtctggatccttactcgaggtcgt attcctcgtatctat-3'), St11-R (5'-tatcatgtctggatccttattcctcgta tctatcacaacaacgat-3'), St16-R (5'-tatcatgtctggatccttaacaaca acgattacacttaagttttc-3'), or St20-R (5'-tatcatgtctggatccttaa cacttaagttttcccatacagtttg-3'), followed by cloning into the BamHI site of pKS336 using an In-Fusion HD Cloning Kit to construct plasmids designated pKS-MERS-St7, pKSMERS-St11, pKS-MERS-St16, and pKS-MERS-St20, respectively.

Human DPP4 cDNA was amplified from Huh-7 cells using the forward primer DPP4-BamF (5'-aggatccaaccatgaagacaccgtggaaggttct-3') and the reverse primer human DPP4-BamR (5'-tggatcctaaggtaaagagaaacattgttttatg-3'), and the product was cloned into the pcDNA3.1(+) mammalian expression vector (Invitrogen, Carlsbad, CA) to form the plasmid pcDNA humanDPP4. Rat DPP4 cDNA was amplified from a rat lung cDNA library (Clontech, Palo Alto, CA) using DPP4-BamF as the forward primer and rat DPP4-BamR as the reverse primer (5'-tggatcctagcgtaaggagaagcactgctggagg-3'), and the product was cloned into pcDNA3.1(+) to form the pcDNA ratDPP4 plasmid. The expression plasmids pcDNA rat-T292L, pcDNA rat-V334R, pcDNA rat-E342Q, and pcDNA rat 3x mut were constructed from pcDNA ratDPP4 by changing Thr to Leu at amino acid residue 292, Val to Arg at amino acid residue 334, Glu to Gln at amino acid residue 342, and the combination of all three of these amino acid substitutions, respectively, by site-directed mutagenesis using oligonucleotides with the corresponding mutations. A 340-bp Pst I fragment (nucleotide position 730 to 1040) of 
rat DPP4 was replaced with the corresponding region of human DPP4 to construct rat DPP4 bearing the receptorbinding domain (RBD)-contacting region (amino acids 251 to 352) of human DPP4 (rat/human chimera).

The cDNAs from the ectodomains of MERS-CoV S and SARS-CoV $S$ were amplified from $\mathrm{pKS}-\mathrm{MERS}-\mathrm{S}$ and $\mathrm{pKS}$ SARS-S [9], respectively, and were cloned into pAcYM1 as described previously [10]. The pAcYM1 vector, which contains a histidine tag sequence in its $\mathrm{C}$-terminal region in the cloned cDNA, was used to construct the transfer plasmids pAcMERS-Sect and pAcSARS-Sect. The cDNA of the full-length MERS-CoV $\mathrm{N}$ protein was amplified from MERS-CoV-infected cells and was cloned into pAcYM1 to form pAcMERS-N.

\section{Rabbit sera}

Rabbit anti-MERS-CoV S, anti-SARS-CoV S, and antiMERS-CoV $\mathrm{N}$ were prepared by immunization of rabbits with recombinant MERS-CoV S, SARS-CoV S, and MERS$\mathrm{CoV} \mathrm{N}$ proteins expressed in a baculovirus expression system.

The procedures used to produce recombinant baculoviruses expressing the ectodomains of MERS-CoV S, SARS-CoV S, and MERS-CoV N using the transfer plasmids pAcMERS-Sect, pAcSARS-Sect, and pAcMERS-N, respectively, were the same as those described previously [10]. The recombinant MERS-CoV S and SARS-CoV S proteins were purified by Ni-column chromatography from culture supernatants of Tn5 cells infected with recombinant baculoviruses, whereas recombinant MERS-CoV $\mathrm{N}$ was purified from Tn5 cell lysates.

\section{Indirect immunofluorescence assay}

Cells transfected with pcDNA bearing human or rat DPP4 were fixed with $10 \%$ formalin under non-permeabilizing conditions and stained with polyclonal goat anti-human DPP4 (R\&D Systems, Minneapolis, MN).

\section{Preparation of pseudotype viruses}

At $24 \mathrm{~h}$ after the transfection of $293 \mathrm{~T}$ cells with pKSMERS-S, pKS-MERS-St7, pKS-MERS-St11, pKS-MERSSt16, or pKS-MERS-St20, the cells were infected with VSV $\Delta \mathrm{G}^{*}$-G/GFP [9] at a multiplicity of infection of 0.1 to prepare MERSpv-Swt, MERSpv-St7, MERSpv-St11, MERSpv-St16, or MERSpv-St20, respectively. As a negative control, 293T cells were mock transfected, and the cells were then infected with VSV $\Delta \mathrm{G}^{*}$-G/GFP to obtain a mock pseudotype. After absorption for $1 \mathrm{~h}$, the inoculum was replaced with culture medium. After a 24-h incubation in a $\mathrm{CO}_{2}$ incubator, the culture supernatants were collected and stored at $-80{ }^{\circ} \mathrm{C}$ for later use. For titration of the pseudotype viruses, Vero cells grown in 96-well plates were inoculated with serially diluted pseudoviruses. At 18 hpi, infection with each pseudotype was detected based on GFP expression observed using a fluorescence microscope. The GFP-expressing cells in the photographic images were counted using a VH analyzer (Keyence, Osaka, Japan). Since the area of the photograph is three times smaller than that of a well in the 96-well plate, the number of GFP-expressing cells in each well was calculated. The pseudotype titers were then expressed as focus-forming units (FFU) per mL.

\section{Pseudotype infection}

Neutralization assays were performed using rabbit antiMERS-CoV S, anti-SARS-CoV S, or anti-MERS-CoV N. Culture medium containing 2,000 infectious units (IU) of MERSpv-St16 was incubated with serially diluted antisera for $1 \mathrm{~h}$ at $37^{\circ} \mathrm{C}$. Then, the mixture was inoculated onto Vero monolayers in 96-well plates. To determine whether DPP4 functions as a receptor, $\mathrm{CHO}$ cells were transfected with expression plasmids encoding human or rat DPP4, or with the control vector. After $48 \mathrm{~h}$, the cells were inoculated with MERSpv-St16. After an 18-h incubation period, the cells were washed with PBS. Cells were photographed under a fluorescence microscope. The GFP-expressing cells in the photographs were counted using counted using a $\mathrm{VH}$ analyzer.

\section{Results}

\section{Generation of a MERS-CoV S-bearing VSV pseudotype}

We have previously shown that C-terminal deletion of the cytoplasmic domain of the SARS-CoV S protein makes it possible to produce a high titer of VSV pseudotype bearing SARS-CoV S [9]. In order to examine the effects of the deletion of the cytoplasmic region on the production of MERS-CoV S-bearing VSV pseudotype (MERSpv), C-terminal truncated mutants of $S$ were constructed (Fig. 1). Infection with MERSpv bearing each $\mathrm{S}$ protein was detected by monitoring GFP expression after inoculating Vero cells with the pseudotypes (Supplementary Fig. 1), and the infectivity was determined by measuring the viral titers (Fig. 1B).

Our results demonstrated that the deletion of amino acid residues from the $\mathrm{C}$-terminus allowed a pseudotype to be produced with a high titer. A pseudotype bearing an $\mathrm{S}$ protein with the C-terminal 16 amino acids deleted (MERSpv-St16) reached a maximum titer that was 


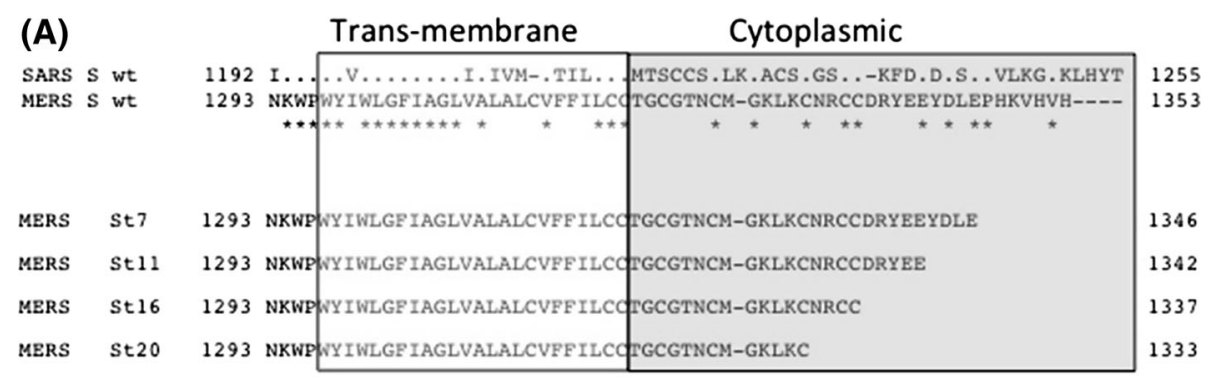

(B)

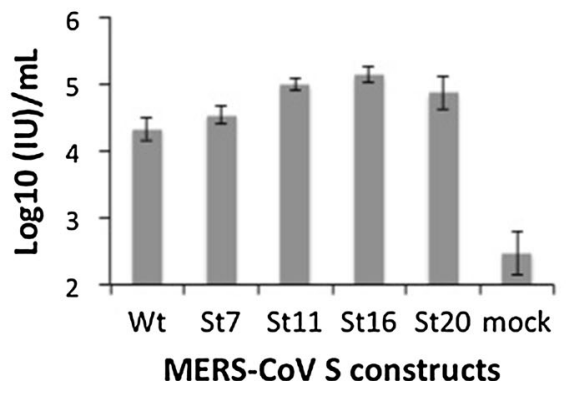

Fig. 1 VSV pseudotyped with cytoplasmic deletion mutants of the S protein. (A) The C-terminal sequences of the MERS-CoV S protein variants used in this study. The C-terminal 19-amino-acid deletion mutant of SARS-CoV $\mathrm{S}$ is shown for comparison. The gray box indicates the cytoplasmic domain. (B) Vero cells were inoculated with

approximately tenfold higher than that of a pseudotype bearing a non-truncated full-length $S$ protein (MERSpvSwt). Similar results were obtained using SARS-CoV with a truncated $S$ protein [9], suggesting that the expression of full-length $\mathrm{S}$ protein on the cell surface may be limited by the presence of an ER-retention signal in its C-terminal cytoplasmic domain, resulting in a very low efficiency of incorporation of the S protein into VSV particles. This hypothesis was supported by the immunofluorescent detection of $S$ protein expression: full-length $S$ protein from MERS-CoV localized around the nucleus, probably in the ER/Golgi region, whereas C-terminally truncated S proteins localized on the cell surface and within the cytoplasm (Supplementary Fig. 2). A detailed study is needed to determine the subcellular localization of $S$ proteins and the amino acid residues that constitute the ER retention signal.

The role of the S protein in MERSpv-St16 infection of Vero cells was examined using rabbit anti-serum immunized with the MERS-CoV S protein. When the MERSpvSt16 was pre-mixed with serially diluted rabbit serum against MERS-CoV $\mathrm{S}$, a significant inhibition of the MERSpv-St16 infection was observed (Fig. 2), whereas rabbit antiserum against SARS-CoV $\mathrm{S}$ or MERS-CoV nucleoprotein $(\mathrm{N})$ did not inhibit infection. This result indicated that the infection of Vero cells with MERSpvSt16 was mediated by the MERS-CoV S protein.
VSV/GFP pseudotyped with deletion mutants. GFP-expressing cells are represented as infectious units (IU). A few GFP-positive cells observed in the mock represent nonspecific infection of the negativecontrol mock pseudotype. The data represent the results from two independent experiments

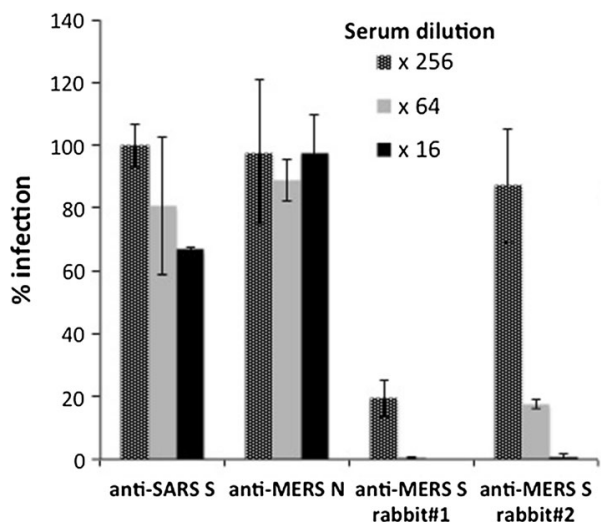

Fig. 2 The specificity of MERSpv-St16 infection in Vero cells. MERSpv-St16 was pre-incubated with serially diluted rabbit antiSARS-CoV S, anti-MERS-CoV N, anti-MERS-CoV S rabbit\#1, or anti-MERS-CoV S rabbit\#2. Then, Vero cells were inoculated with the mixture. The number of GFP-positive cells in the absence of antibodies was set as $100 \%$. The data represent the results from two independent experiments

\section{Rat DPP4 does not act as a receptor for MERS-CoV}

Based on the results described above, it was clear that MERSpv-St16 could be applied directly to analyze the process of MERS-CoV entry. MERS-CoV is capable of infecting a variety of cells in a DPP4-dependent manner. The critical amino acids of DPP4 that are responsible for 
Fig. 3 Rat DPP4 does not act as a MERS-CoV receptor. (A) The expression of DPP4 on $\mathrm{CHO}$ cells. $\mathrm{CHO}$ cells were transfected with expression plasmids encoding human and rat DPP4. Empty pcDNA was used as a negative control. The expression of DPP4 was detected using an anti-human DPP4 polyclonal antibody, followed by a FITC-labeled anti-goat antibody. (B) Cells transfected with expression plasmids encoding human or rat DPP4 or the pcDNA vector were inoculated with MERSpvSt16 (MOI $=0.2)$. GFP expression was examined by fluorescence microscopy. (C) Cells transfected with expression plasmids encoding human or rat DPP4 or the pcDNA vector were inoculated with MERS-CoV $(\mathrm{MOI}=0.1)$. At 48 hours postinfection, the cells were stained with antiMERS N rabbit serum

(A)

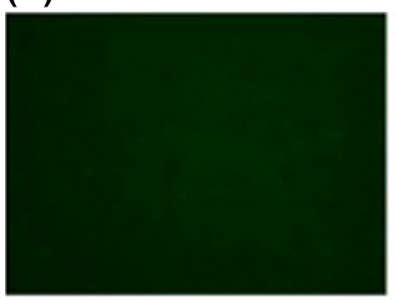

(B)

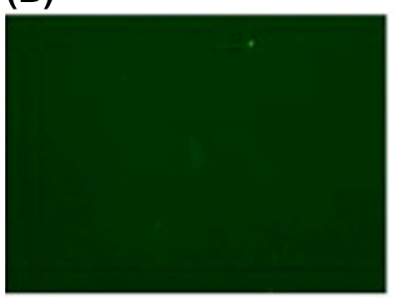

pcDNA

(C)

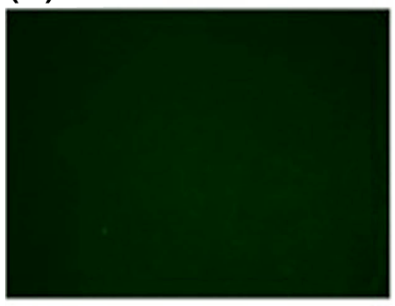

pcDNA

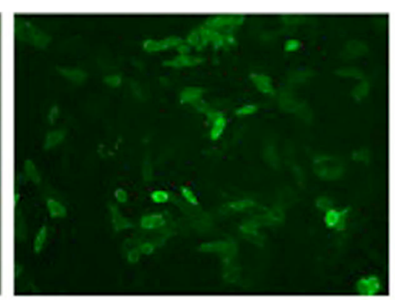

rat DPP4

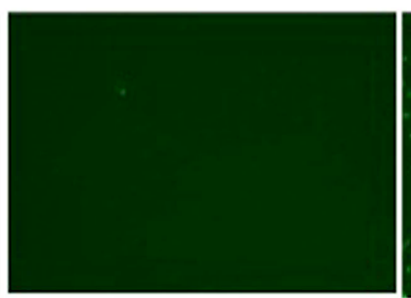

rat DPP4

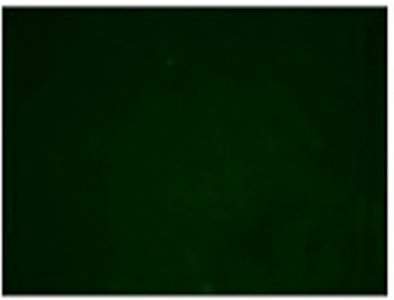

rat DPP4

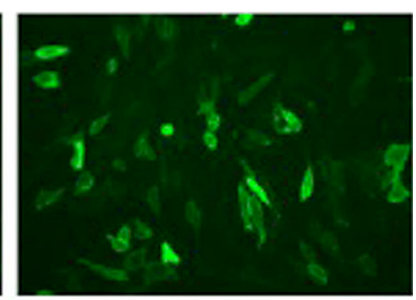

human DPP4

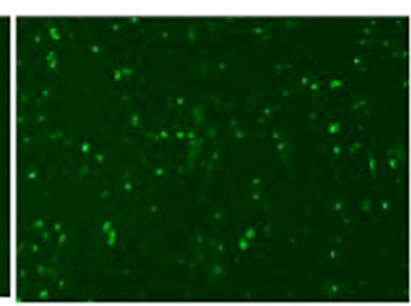

human DPP4

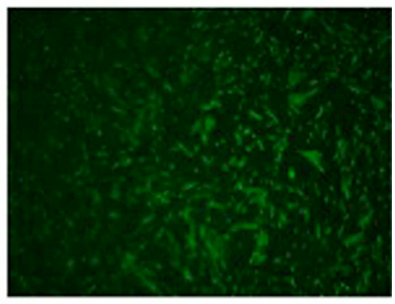

human DPP4 binding to the $S$ protein have been identified by structural analysis, but they vary among animal species [3]. DPP4 proteins derived from mice and hamsters are not functional receptors for MERS-CoV infection [6, 23]. An analysis of the function of DPP4 from different animal species on the subsequent MERS-CoV infection might provide novel information regarding the host range of MERS-CoV. Therefore, we examined whether the expression of DPP4 from rats, another commonly used small-animal model, supports infection by MERS-CoV. Human and rat DPP4 were expressed in $\mathrm{CHO}$ cells, and their expression was confirmed by an immunofluorescence assay (IFA; Fig. 3A). Upon infection with MERSpv-St16 (MOI = 0.2), the expression of GFP was easily detected in the human DPP4-expressing cells. In contrast, there was a limited amount of infection of MERSpv-St16 in the rat DPP4expressing cells, which was comparable to that of control cells that did not express DPP4 (Fig. 3B), indicating the inability of rat DPP4 to mediate MERSpv-St16 infection. This conclusion was confirmed using MERS-CoV: the expression of MERS-CoV nucleoprotein (N) was detected after inoculation of human DPP4-expressing cells with MERS-CoV (MOI = 1.0), whereas no expression of MERS-CoV N was detected in cells expressing rat DPP4 (Fig. 3C).

\section{Mutational analysis of rat DPP4}

Comparisons of the amino acid residues of human and bat DPP4 that are critical for making contact with the RBD of MERS-CoV S with the corresponding residues of rat DPP4 suggested that differences in the amino acid residues 292, 334, and/or 342 may account for the differences in susceptibility to MERS-CoV infection [3] (Table 1). The threonine residue at position 293 of rat DPP4 was not included in the mutational analysis because bat DPP4, which contains a threonine residue at position 293 (Table), supports MERS-CoV infection [19]. Furthermore, mutational studies by Raj et al. [20] demonstrated that the amino acid substitution I293T (amino acid residue 295 in their study) in human DPP4 did not significantly decrease binding of MERS-CoV S1, suggesting that amino acid residue 293 of rat DPP4 is not a critical determinant of the inability of rat DPP4 to serve as a functional receptor for MERS-CoV. We examined whether the substitution of these amino acids of rat DPP4 with human DPP4 would lead to a gain of receptor activity. Rat DPP4 mutants were expressed in $\mathrm{CHO}$ cells and found to have similar expression levels (Supplementary Fig. 3). CHO cells expressing rat DPP4 bearing a single amino acid substitution with the amino acid from human DPP4 at position 292, 
Table 1 DPP4 residues in contact with RBD of MERS$\mathrm{CoV}$

\begin{tabular}{llllllllllll}
\hline DPP4 & \multicolumn{10}{l}{ RBD-contacting residues in DPP4* } \\
\cline { 2 - 10 } & 265 & 284 & 286 & 289 & 292 & 293 & 315 & 320 & 334 & 342 & 344 \\
\hline Human & $\mathrm{K}$ & $\mathrm{Q}$ & $\mathrm{T}$ & $\mathrm{A}$ & $\mathrm{L}$ & $\mathrm{I}$ & $\mathrm{R}$ & $\mathrm{Y}$ & $\mathrm{R}$ & $\mathrm{Q}$ & $\mathrm{I}$ \\
Bat & $\mathrm{K}$ & $\mathrm{Q}$ & $\mathrm{T}$ & $\mathrm{A}$ & $\mathrm{L}$ & $\mathrm{T}^{\dagger}$ & $\mathrm{R}$ & $\mathrm{Y}$ & $\mathrm{K}^{\dagger}$ & $\mathrm{Q}$ & $\mathrm{I}$ \\
Rat & $\mathrm{K}$ & $\mathrm{Q}$ & $\mathrm{T}$ & $\mathrm{A}$ & $\mathrm{T}^{\dagger}$ & $\mathrm{T}^{\dagger}$ & $\mathrm{R}$ & $\mathrm{Y}$ & $\mathrm{V}^{\dagger}$ & $\mathrm{E}^{\dagger}$ & $\mathrm{I}$ \\
Mouse & $\mathrm{K}$ & $\mathrm{Q}$ & $\mathrm{P}^{\dagger}$ & $\mathrm{A}$ & $\mathrm{A}^{\dagger}$ & $\mathrm{R}^{\dagger}$ & $\mathrm{R}$ & $\mathrm{Y}$ & $\mathrm{T}^{\dagger}$ & $\mathrm{Q}$ & $\mathrm{V}^{\dagger}$ \\
\hline
\end{tabular}

* The position of amino acid residues refers to the rat DPP4

$\dagger$ The amino acid residue differs from that of human DPP4

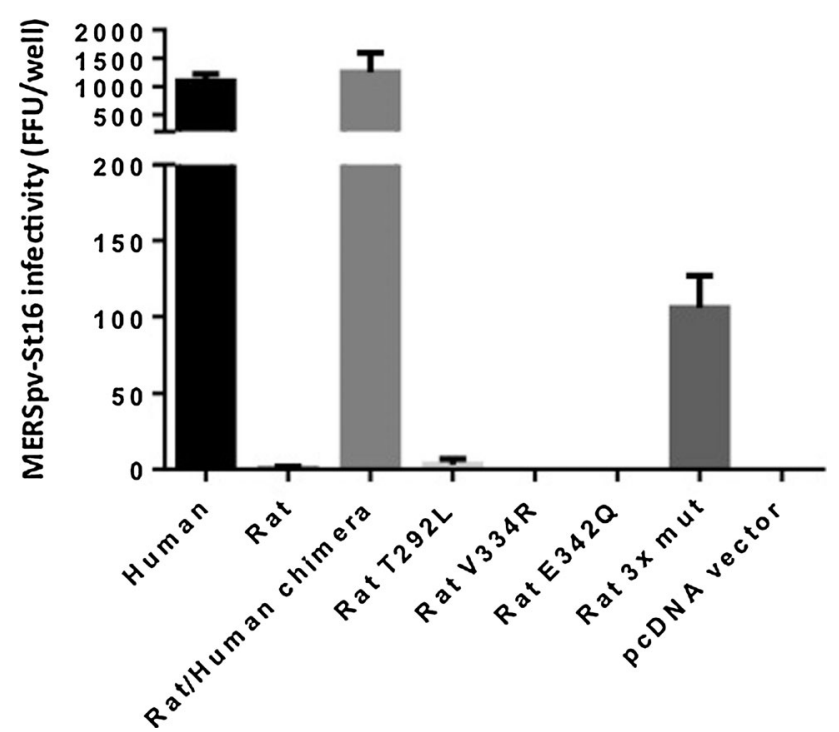

Fig. 4 Mutational analysis of rat DPP4. CHO cells transfected with expression plasmids encoding human DPP4, rat DPP4, or rat DPP4 mutants were inoculated with MERSpv-St16. GFP expression was examined by fluorescence microscopy, and the number of the GFPpositive cells was determined

334, or 342 (Rat T292L, V334R, or E342Q) did not support MERSpv-St16 infection (Fig. 4). However, the level of infection of cells expressing rat DPP4 bearing a combination of all three amino acid substitutions (Rat 3x mut) was increased to $10 \%$ of the level of cells expressing human DPP4. These results indicated that the three amino acids at positions 292, 334, and 342 are major determinants of the inability of rat DPP4 to serve as a functional receptor for MERS-CoV. Alignment of rat DPP4 and human DPP4 sequences showed amino acid sequence variations surrounding the RBD-contacting region (amino acids 251 to 352 ), which may account for the difference in the MERS$\mathrm{CoV}$ receptor functions (Supplementary Fig. 4). We then constructed rat DPP4 bearing the amino acids 251 to 352 of human DPP4 (rat/human chimera). Infection of cells expressing rat/human chimera DPP4 with MERSpv-St16 gave results comparable to those for the cells expressing human DPP4, suggesting that amino acid residues in the
RBD-contacting region other than those at positions 292 , 334 , and 342 are also required for the most efficient use of the entry receptor.

\section{Discussion}

In this study, we demonstrated that a MERS-CoV S variant with a 16-amino acid deletion in cytoplasmic domain formed VSV pseudotypes with a higher titer than the other variants tested. It is likely that the inefficient incorporation of full-length S protein into VSV particles is due to an ER retention signal in the C-terminal portion of the cytoplasmic domain, which prevents intracellular transport and surface expression of the $\mathrm{S}$ protein. This assumption was supported by the findings that C-terminally truncated $\mathrm{S}$ proteins showed a different cellular localization pattern when compared with that of the full-length MERS-CoV S protein. It has been reported that MERS-CoV S-bearing pseudotypes with an HIV backbone $[18,26]$ are useful for detecting neutralization antibodies in serum samples and may provide a safe and specific assay tool for large-scale seroepidemiological studies. Virus neutralization is the most specific serological assay and is currently considered the gold standard. Barlan et al. [2] reported a VSV-based MERS-CoV-S-bearing pseudotype and used it to analyze the cell entry of MERS-CoV. It is of great interest to clarify whether MERSpv can be applied for neutralization assays with high specificity. Here, we demonstrate that VSVbased MERSpv-St16 infection was inhibited by antiMERS-CoV-S, but not by anti-MERS-CoV-N or antiSARS-CoV-S, and that infection was dependent on the expression of DPP4 (Figs. 2 and 4), indicating that the MERSpv-St16 infection is mediated by the interaction of MERS-CoV S with its receptor, DPP4.

A major advantage of using MERSpv for neutralization assays is that infection can be detected earlier when using a VSV backbone than when using a lentivirus backbone. Furthermore, VSV pseudotypes can be applied for highthroughput screening for neutralizing antibodies [4]. MERSpv-St16 may be a useful reagent that can provide a 
safe and convenient alternative to neutralization assays using live MERS-CoV.

Cells expressing DPP4 from humans, bats, macaques, and livestock (including camels, cows, and goats) are susceptible to MERS-CoV infection, whereas those of mice and hamsters, which are often used as small-animal models to study viral infections, are not susceptible $[6,23]$. The amino acid sequences of DPP4 that are critical for binding to the RBD of the $\mathrm{S}$ protein vary among animal species (Table 1). There are five different amino acid residues in the RBD-contacting region between human and mouse DPP4. In contrast, rat DPP4 shows a different amino acid sequence in the RBD-contacting region; it has four amino acid differences from human DPP4 and only three from bat DPP4. In the present study, the ability of rat-derived DPP4 to serve as a receptor for MERS-CoV was investigated using MERSpv-St16. We demonstrated that MERSpv-St16 did not infect cells expressing rat DPP4. This result was consistent with what was observed using MERS-CoV (Fig. 3). We thus concluded that rat DPP4 did not function as a receptor for MERS-CoV. Our findings, in combination with studies published by others, indicate that rodents are not susceptible to MERS-CoV infection.

A mutational analysis of rat DPP4 suggested that individual amino acid differences at positions 292, 334, and 342 were not responsible for the inability of DPP4 to function as a MERS-CoV receptor. In contrast, it has been shown that a single substitution in the RBD-contacting region of mouse DPP4 with the corresponding residue of human DPP4 allows MERS-CoV infection, although to a lesser extent than that observed in human cells [6]. It has also been suggested that a potential glycosylation site at position 330 of mouse DPP4 might have an inhibitory effect on the interaction between mouse DPP4 and the RBD of the S protein [6]. However, of the four amino acid residues of rat DPP4 that are different from those of human DPP4 in the RBD-contacting region, none appear to be within a potential glycosylation motif. This suggests that the glycosylation of amino acid(s) critical for contact with the $S$ protein does not lead to potential spatial interference between MERS-CoV S and rat DPP4. It has also been speculated that the inhibitory effects of the RBD-contacting region of DPP4 are different between mouse and rat DPP4.

In conclusion, we have demonstrated that deletion of 16 amino acids from the carboxyl-terminal end of MERS-CoV $S$ led to an increased efficiency of infection, allowing the production of a high titer of VSV pseudotype bearing S protein (MERSpv-St16). The MERSpv-St16 can be used for safe, rapid, and convenient neutralization assays for laboratory diagnosis of MERS. Furthermore, using MERSpv-St16, we also demonstrated that rat DPP4 was not a functional receptor for MERS-CoV. This study provides novel information regarding the host range of MERS-CoV. A detailed structural and mutational analysis will be required to clarify how the amino acid residues of rat DPP4 prevent the binding of the MERS-CoV S protein.

Acknowledgments We thank Dr. Bart Haagmans and Dr. Ron Fouchier, Erasmus Medical Center, Rotterdam, The Netherlands, for providing MERS-CoV, and Dr. Kazuo Ohnishi, National Institute of Infectious Diseases, for providing a monoclonal antibody for MERS$\mathrm{CoV} \mathrm{S}$ protein. We also thank Dr. Shutoku Matsuyama and Dr. Masato Tashiro, National Institute of Infectious Diseases, for experimental support and helpful discussions. This work was supported in part by a grant-in-aid from the Ministry of Health, Labor, and Welfare of Japan (H25 Shinko-Ippan-008) and JSPS KAKENHI Grant Number 26450418 .

\section{References}

1. Abroug F, Slim A, Ouanes-Besbes L, Hadj Kacem MA, Dachraoui F, Ouanes I, Lu X, Tao Y, Paden C, Caidi H, Miao C, Al-Hajri MM, Zorraga M, Ghaouar W, BenSalah A, Gerber SI (2014) Family cluster of Middle East respiratory syndrome coronavirus infections, Tunisia, 2013. Emerg Infect Dis 20:1527-1530

2. Barlan A, Zhao J, Sarkar MK, Li K, McCray PB Jr, Perlman S, Gallagher T (2014) Receptor variation and susceptibility to Middle East respiratory syndrome coronavirus infection. J Virol 88:4953-4961

3. Bosch BJ, Raj VS, Haagmans BL (2013) Spiking the MERScoronavirus receptor. Cell Res 23:1069-1070

4. Bukbuk DN, Fukushi S, Tani H, Yoshikawa T, Taniguchi S, Iha K, Fukuma A, Shimojima M, Morikawa S, Saijo M, Kasolo F, Baba SS (2014) Development and validation of serological assays for viral hemorrhagic fevers and determination of the prevalence of Rift Valley fever in Borno State, Nigeria. Trans R Soc Trop Med Hyg 108:768-773

5. Chan JF, Chan KH, Choi GK, To KK, Tse H, Cai JP, Yeung ML, Cheng VC, Chen H, Che XY, Lau SK, Woo PC, Yuen KY (2013) Differential cell line susceptibility to the emerging novel human betacoronavirus 2c EMC/2012: implications for disease pathogenesis and clinical manifestation. J Infect Dis 207:1743-1752

6. Cockrell AS, Peck KM, Yount BL, Agnihothram SS, Scobey T, Curnes NR, Baric RS, Heise MT (2014) Mouse dipeptidyl peptidase 4 is not a functional receptor for Middle East respiratory syndrome coronavirus infection. J Virol 88:5195-5199

7. Falzarano D, de Wit E, Feldmann F, Rasmussen AL, Okumura A, Peng X, Thomas MJ, van Doremalen N, Haddock E, Nagy L, LaCasse R, Liu T, Zhu J, McLellan JS, Scott DP, Katze MG, Feldmann H, Munster VJ (2014) Infection with MERS-CoV causes lethal pneumonia in the common marmoset. PLoS Pathog 10:e1004250

8. Fanoy EB, van der Sande MA, Kraaij-Dirkzwager M, Dirksen K, Jonges M, van der Hoek W, Koopmans MP, van der Werf D, Sonder G, van der Weijden C, van der Heuvel J, Gelinck L, Bouwhuis JW, van Gageldonk-Lafeber AB (2014) Travel-related MERS-CoV cases: an assessment of exposures and risk factors in a group of Dutch travellers returning from the Kingdom of Saudi Arabia, May 2014. Emerg Themes Epidemiol 11:16

9. Fukushi S, Mizutani T, Saijo M, Matsuyama S, Miyajima N, Taguchi F, Itamura S, Kurane I, Morikawa S (2005) Vesicular stomatitis virus pseudotyped with severe acute respiratory syndrome coronavirus spike protein. J Gen Virol 86:2269-2274 
10. Fukushi S, Nakauchi M, Mizutani T, Saijo M, Kurane I, Morikawa S (2012) Antigen-capture ELISA for the detection of Rift Valley fever virus nucleoprotein using new monoclonal antibodies. J Virol Methods 180:68-74

11. Kraaij-Dirkzwager M, Timen A, Dirksen K, Gelinck L, Leyten E, Groeneveld P, Jansen C, Jonges M, Raj S, Thurkow I, van Gageldonk-Lafeber R, van der Eijk A, Koopmans M (2014) Middle East respiratory syndrome coronavirus (MERS-CoV) infections in two returning travellers in the Netherlands, May 2014. Euro Surveill 19

12. Lu G, Hu Y, Wang Q, Qi J, Gao F, Li Y, Zhang Y, Zhang W, Yuan Y, Bao J, Zhang B, Shi Y, Yan J, Gao GF (2013) Molecular basis of binding between novel human coronavirus MERS-CoV and its receptor CD26. Nature 500:227-231

13. Moore MJ, Dorfman T, Li W, Wong SK, Li Y, Kuhn JH, Coderre J, Vasilieva N, Han Z, Greenough TC, Farzan M, Choe H (2004) Retroviruses pseudotyped with the severe acute respiratory syndrome coronavirus spike protein efficiently infect cells expressing angiotensin-converting enzyme 2. J Virol 78:10628-10635

14. Muller MA, Raj VS, Muth D, Meyer B, Kallies S, Smits SL, Wollny R, Bestebroer TM, Specht S, Suliman T, Zimmermann K, Binger T, Eckerle I, Tschapka M, Zaki AM, Osterhaus AD, Fouchier RA, Haagmans BL, Drosten C (2012) Human coronavirus EMC does not require the SARS-coronavirus receptor and maintains broad replicative capability in mammalian cell lines. MBio 3

15. Munster VJ, de Wit E, Feldmann H (2013) Pneumonia from human coronavirus in a macaque model. $\mathrm{N}$ Engl $\mathrm{J}$ Med 368:1560-1562

16. Nowotny N, Kolodziejek J (2014) Middle East respiratory syndrome coronavirus (MERS-CoV) in dromedary camels, Oman, 2013. Euro Surveill 19:20781

17. Ogino M, Ebihara H, Lee BH, Araki K, Lundkvist A, Kawaoka Y, Yoshimatsu K, Arikawa J (2003) Use of vesicular stomatitis virus pseudotypes bearing hantaan or seoul virus envelope proteins in a rapid and safe neutralization test. Clin Diagn Lab Immunol 10:154-160

18. Perera RA, Wang P, Gomaa MR, El-Shesheny R, Kandeil A, Bagato O, Siu LY, Shehata MM, Kayed AS, Moatasim Y, Li M, Poon LL, Guan Y, Webby RJ, Ali MA, Peiris JS, Kayali G (2013) Seroepidemiology for MERS coronavirus using microneutralisation and pseudoparticle virus neutralisation assays reveal a high prevalence of antibody in dromedary camels in Egypt, June 2013. Euro Surveill 18:pii=20574

19. Raj VS, Mou H, Smits SL, Dekkers DH, Muller MA, Dijkman R, Muth D, Demmers JA, Zaki A, Fouchier RA, Thiel V, Drosten C, Rottier PJ, Osterhaus AD, Bosch BJ, Haagmans BL (2013)
Dipeptidyl peptidase 4 is a functional receptor for the emerging human coronavirus-EMC. Nature 495:251-254

20. Raj VS, Smits SL, Provacia LB, van den Brand JM, Wiersma L, Ouwendijk WJ, Bestebroer TM, Spronken MI, van Amerongen G, Rottier PJ, Fouchier RA, Bosch BJ, Osterhaus AD, Haagmans BL (2014) Adenosine deaminase acts as a natural antagonist for dipeptidyl peptidase 4-mediated entry of the Middle East respiratory syndrome coronavirus. J Virol 88:1834-1838

21. Reusken CB, Haagmans BL, Muller MA, Gutierrez C, Godeke GJ, Meyer B, Muth D, Raj VS, Smits-De Vries L, Corman VM, Drexler JF, Smits SL, El Tahir YE, De Sousa R, van Beek J, Nowotny N, van Maanen K, Hidalgo-Hermoso E, Bosch BJ, Rottier P, Osterhaus A, Gortazar-Schmidt C, Drosten C, Koopmans MP (2013) Middle East respiratory syndrome coronavirus neutralising serum antibodies in dromedary camels: a comparative serological study. Lancet Infect Dis 13:859-866

22. Tsiodras S, Baka A, Mentis A, Iliopoulos D, Dedoukou X, Papamavrou G, Karadima S, Emmanouil M, Kossyvakis A, Spanakis N, Pavli A, Maltezou H, Karageorgou A, Spala G, Pitiriga V, Kosmas E, Tsiagklis S, Gkatzias S, Koulouris N, Koutsoukou A, Bakakos P, Markozanhs E, Dionellis G, Pontikis K, Rovina N, Kyriakopoulou M, Efstathiou P, Papadimitriou T, Kremastinou J, Tsakris A, Saroglou G (2014) A case of imported Middle East Respiratory Syndrome coronavirus infection and public health response, Greece, April 2014. Euro Surveill 19:20782

23. van Doremalen N, Miazgowicz KL, Milne-Price S, Bushmaker T, Robertson S, Scott D, Kinne J, McLellan JS, Zhu J, Munster VJ (2014) Host species restriction of Middle East respiratory syndrome coronavirus through its receptor, dipeptidyl peptidase 4 . J Virol 88:9220-9232

24. Wang N, Shi X, Jiang L, Zhang S, Wang D, Tong P, Guo D, Fu L, Cui Y, Liu X, Arledge KC, Chen YH, Zhang L, Wang X (2013) Structure of MERS-CoV spike receptor-binding domain complexed with human receptor DPP4. Cell Res 23:986-993

25. Zaki AM, van Boheemen S, Bestebroer TM, Osterhaus AD, Fouchier RA (2012) Isolation of a novel coronavirus from a man with pneumonia in Saudi Arabia. N Engl J Med 367:1814-1820

26. Zhao G, Du L, Ma C, Li Y, Li L, Poon VK, Wang L, Yu F, Zheng BJ, Jiang S, Zhou Y (2013) A safe and convenient pseudovirusbased inhibition assay to detect neutralizing antibodies and screen for viral entry inhibitors against the novel human coronavirus MERS-CoV. Virol J 10:266

27. Zhao J, Li K, Wohlford-Lenane C, Agnihothram SS, Fett C, Gale MJ Jr, Baric RS, Enjuanes L, Gallagher T, McCray PB Jr, Perlman S (2014) Rapid generation of a mouse model for Middle East respiratory syndrome. Proc Natl Acad Sci USA 111:4970-4975 